\title{
Influence of length of glass fibers in recycled polypropylene on tensile properties
}

\author{
Vojtech Senkerik ${ }^{1, a}$, Michal Stanek ${ }^{1}$, David Manas ${ }^{1}$, Miroslav Manas ${ }^{1}$, Vaclav Janostik ${ }^{1}$ and Martin Ovsik ${ }^{1}$ \\ ${ }^{1}$ Tomas Bata University in Zlin, nam. T. G. Masaryka 5555, 76001 Zlin, Czech Republic
}

\begin{abstract}
The purpose of this article is to show the influence of grinded glass fibers in polymer material. Tested samples were processed by injection molding. Waste from this production was subsequently ground and a mixture was obtained with different size of crushed material. These particles contains glass fibers of similar length as the specific size of particle. Thus very small particles contain very short fibers. Investigation was carried out by testing tensile properties on material polypropylene with $30 \%$ glass fibers. Testing was conducted at ambient temperatures. The effect of reprocessing of material is mainly represented by fiber shortening. As a result, considerable reduction of tensile properties can be observed. The reduction is most evident in the modules of elasticity and ultimate tensile strength.
\end{abstract}

\section{Introduction}

Products made by injection molding have either character of final product or are semi products for consequent assembly into next complex product. Products made by injection molding are distinguished by very precise dimensions and shape, and also by great reproducibility of mechanic and physical properties. Injection molding technology is most wide-spread technology in plastic manufacturing; it is discontinuous and cyclic process. Almost all kinds of thermoplastics can be injected. Some thermosetting polymer and rubbers can be injected as well.

Defective injects, waste and runner system originating during injection molding can be processed several times. This way of processing is frequently used because of high portion of the waste, especially while manufacturing small injects. For this reason is unpolluted waste cut and crushed. Material modified by this process is once again granulated and mixed with pure granulate and consequently utilized. Using this mixed material has usually no significant influence on physical-mechanical properties or surface appearance. Level of properties degradation depends on levels of crushed material in original material. Transparent and highly stressed materials cannot be mixed, because of high demands.

Injected product can be made even with fifteen to thirty percent amount of waste in origin material without significant influence on its properties. Material properties gradually decrease with higher percents of waste in mix. In some cases (low-end simple injects) parts can be made even from hundred percent of waste.
Mechanical recycling consists in recovering waste material by means of thermos-physical processes. This recycling of plastics presents several technical, economical and marketing challenges.

Mechanical recycling is the most common method of recycling. Here plastics are physically ground back to a suitable size (regrind) and reprocessed. The end use can be the original one or something different.

In the plastics industry it has long been common practice to reprocess waste material arising from normal production. This in-house recycling, known as primary recycling, makes economic sense as it reduces both production waste and utilisation of raw materials. For example, with injection moulding, regrind from start-up waste and production waste such as reject parts, can be fed directly back into the production machine.

In general, variability of product composition and color leads to difficulties in obtaining a product with a consistent set of properties, and sourcing an adequate supply of a reasonably clean feedstock is often the crucial step in determining the economics of the recycling process and the quality of the recycled products. Processability and physical properties of recycled products can be considerably deteriorated with respect to virgin polymers. This is mainly due to the following effect polymer degradation.

Degradation of polymers are subject to negative changes in their macroscopic properties due to subtle modification of molecular structure that can result from the following environmental factors: thermal-oxidative processes that can occur during molding or even at room temperature, attack by pollutant gasses, chemical interaction with liquid contents, and others.

\footnotetext{
a Corresponding author: vsenkerik@ft.utb.cz
} 
Degradative processes are often accelerated by the presence of certain impurities.

Glass fibers are one of the most cost-effective reinforcements for plastics. Chopped glass fibers can be compounded with thermoplastics to obtain products with improved property sets. They are easily obtainable from a range of manufactures and their production process is quite energy efficient, so that their use into products does not significantly affect the environmental performance.

Mechanical recycling of thermoplastics materials with glass fibers consists of granulating and re-molding, without separating reinforcing fibers from matrix. Then the material is reused still as composite. The fiber length distribution and the bonding between the glass fibers and the polymer are affected by the injection molding process. Bonding can be improved by using coupling agents or by incorporating recycled material into virgin material, but fiber shortening constitutes an important issue for safely using recycled fiber reinforced materials. [1-11]

\section{Experiment}

The aim of this work is to study the effect of particle size of recycled polymeric material to mechanical properties. The goal is to perform an experiment in which the products of the studied polymer will be crushed to crushed material (recycled material) and then reprocessed into new products. These are then subjected to tensile mechanical testing.

Polymer used for this work is an injection molding grade Syntegum 2030 AFV. It is compound on homopolymer polypropylene, reinforced with 30 percentage chemical couple glass fibers. And this PP is suitable for the production of high-technological products, which in normal working conditions are submitted to high temperatures and considerable mechanical stress.

The in-plant recycling of the virgin polypropylene consisted of grinding of tensile test specimens in a knife mill type GK 2218 from producer Maskain AB Rapid. The output of the knife mill was mixed crushed material containing many particles of various sizes up to a fine powder.

Sieving of material immediately follows grinding. The purpose of the sifting was to group the particles of certain sizes of non-sieved crushed recycled material. Sieving was carried out on laboratory sieve shakers AS 200 Basic. The specimens were prepared by the injection molding technology on the injection molding machine. Process conditions were set according to the recommended values according to the material manufacturer.

\section{SPECIMENS}

Different compositions were prepared for the measurements of tested mixtures with differing sizes of sieved particles.

Virgin PP - material directly from the manufacturer which has not yet been processed in any way, it is taken as a referential material, length of cylindrical granules is $3.5 \mathrm{~mm}$.

PP 5 - $4 \mathrm{~mm}$ - sieved recycled material with a particle size bigger than $4 \mathrm{~mm}$ - this particles stay on sieve with holes $4 \mathrm{~mm}$ and chopped fibers are at least due to the length size of the polymer particles (in Figure 1).

PP $4-3 \mathrm{~mm}$ - sieved recycled material with a particle size from $4 \mathrm{~mm}$ to $3 \mathrm{~mm}$, these particles are similar in size as the original virgin granule.

PP $3-2 \mathrm{~mm}$ - sieved recycled material with a particle size from $3 \mathrm{~mm}$ to $2 \mathrm{~mm}$.

PP 2-1 $\mathrm{mm}$ - sieved recycled material with a particle size from $2 \mathrm{~mm}$ to $1 \mathrm{~mm}$.

PP $1-0 \mathrm{~mm}$ - sieved recycled material with a particle size from $1 \mathrm{~mm}$ to $0 \mathrm{~mm}$, containing very small to dust particles and therefore the shortening of the fibers is the greatest (in Figure 2).

Non-sieved crushed PP - this recycled material is collected directly from the knife mill, contains particles of all sizes, from large particles to dust particles and therefore is heterogeneous.

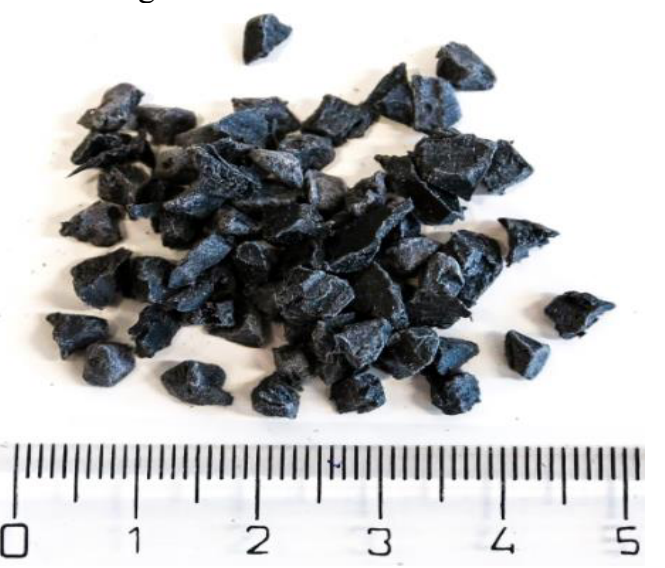

Figure 1. PP 5-4 mm mixture.

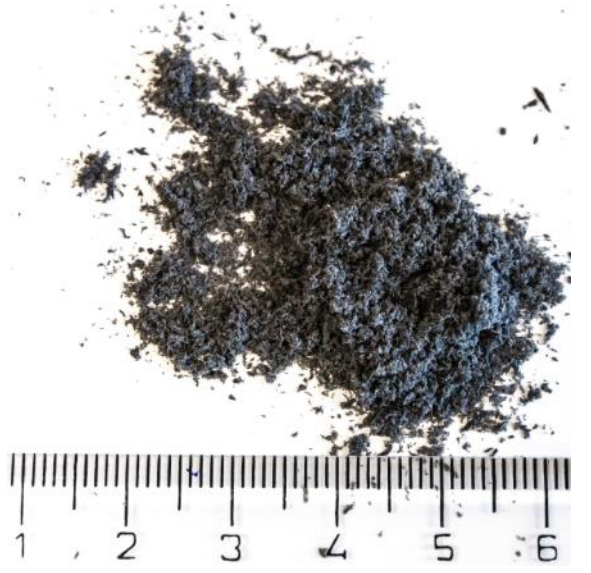

Figure 2. PP $1-0 \mathrm{~mm}$ mixture.

Figure 3 shows the weight ratio of particle size of the total grinded mixture. It shows that the largest proportion of the recycled particles between $4-3 \mathrm{~mm}$, of the total volume of them present in almost half.

Particles 3-2 $\mathrm{mm}$ representing a further $41 \%$ by weight. Other particles represent only a small percentage. Finally, the dust particles occupy only $1 \%$ of the total weight. 


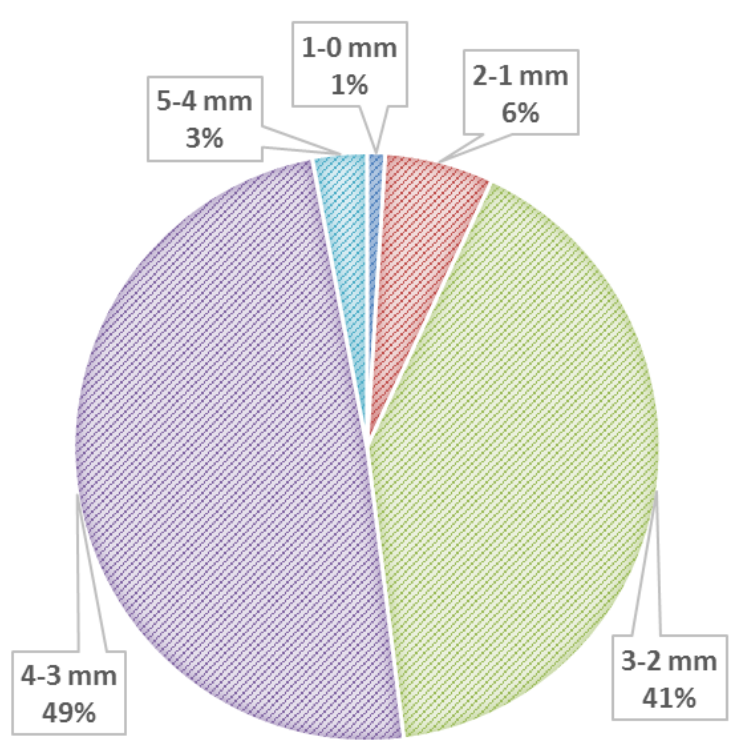

Figure 3. Weight ratio of particle size of the total grinded mixture.

\section{Testing}

Mechanical testing consisted of tensile test. Tensile properties were measured in accordance with the procedure in EN ISO 527 standard on a universal tensile testing machine 1456 from Zwick / Roel. Testing was conducted at ambient temperature $23^{\circ} \mathrm{C}$.

\section{Results}

All graphs are normalized that the virgin material is $100 \%$. Other values are scaled to this value.

\subsection{Elastic tensile modulus}

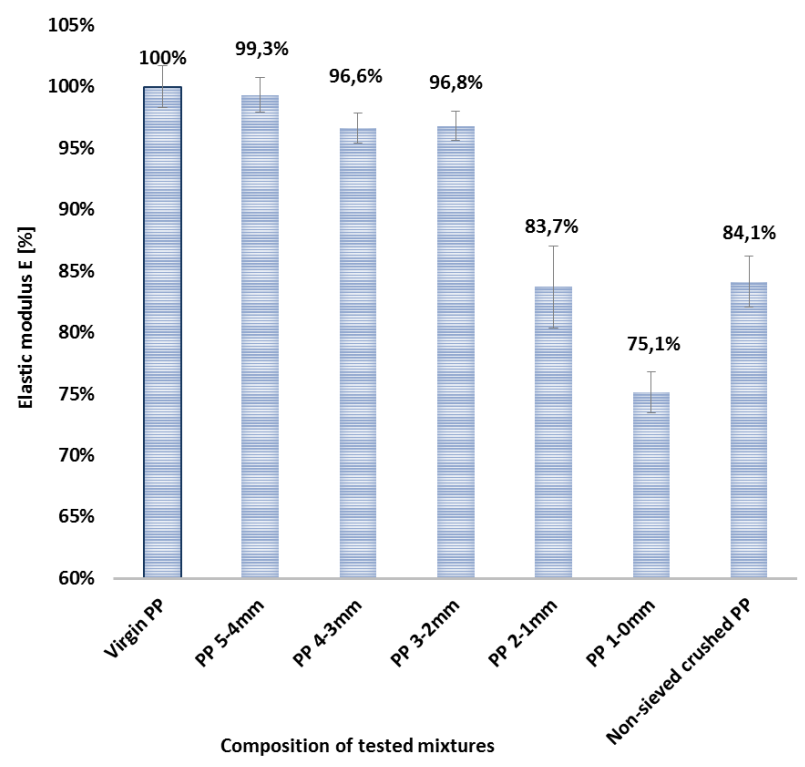

Figure 4. Elastic modulus.
From Figure 4 is can be seen that elastic modulus is reduced by only about $3 \%$ for mixtures with crushed size greater than $2 \mathrm{~mm}$, from the original value $6530 \mathrm{MPa}$ to $6300 \mathrm{MPa}$. This reduction leads to further reducing the particle size to a value of $4900 \mathrm{MPa}$ for the smallest size of particles, which when compared with the virgin PP represents a reduction of $25 \%$.

Negative effect of particle size when decreasing the particle size can be seen on rapid deterioration of elastic modulus at room temperature of the tested material. In non-sieved crushed material containing both small and large particles the modulus is decreased by $16 \%$.

\subsection{Ultimate tensile strength}

In Figure 5 shows the effect of fillers on tensile strength at room temperature. From results it can be observed even greater influence on the composite with small particle size, which is changed to $28 \%$ from the virgin PP.

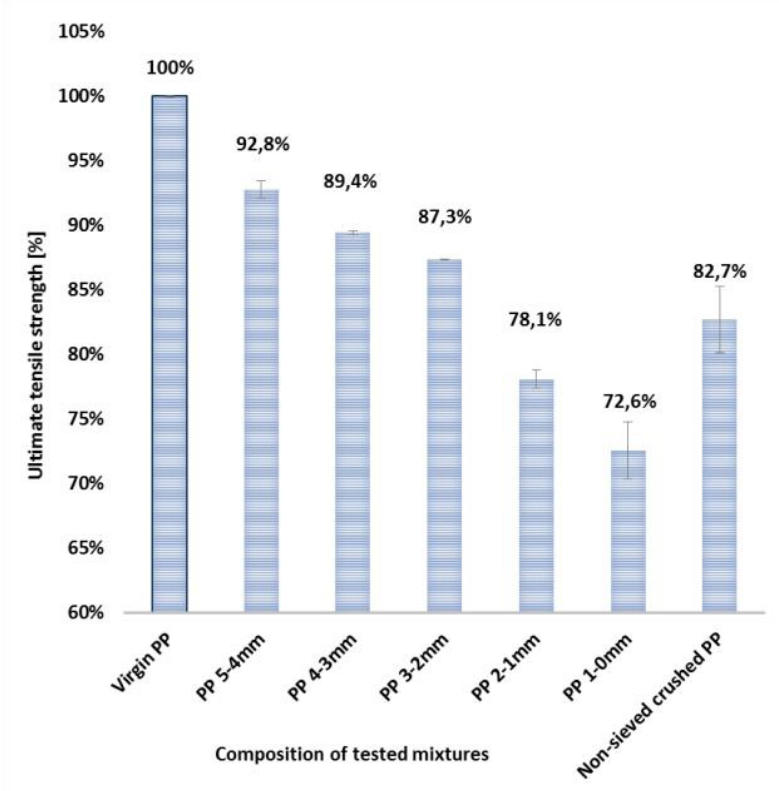

Figure 5. Ultimate tensile strength.

For the composite with the greatest length recycled material and therefore the least shortening of glass fibers was reduced strength only $7 \%$. Overall, there was a significant drop in tensile strength at room temperature of $89 \mathrm{MPa}$ for virgin PP to the $65 \mathrm{MPa}$. Non-sieved crushed material shows similar reduction in tension as in the previous case of tensile modulus.

\subsection{Strain}

The decreasing strength and tensile modulus also entails disadvantages in the form of increasing strain (Figure 6). Mixture with particle size $5-4 \mathrm{~mm}$ has been reduced by only $1 \%$ compared to the virgin PP. Non-sieved crushed mixture shows a similar elongation.

Further reducing particle size and therefore the filler size decreased elongation in tension up to $5 \%$ of its initial 
value. From the obtained results can be concluded that the lower the value of modulus respectively tensile strength leads to a greater resulting strain.

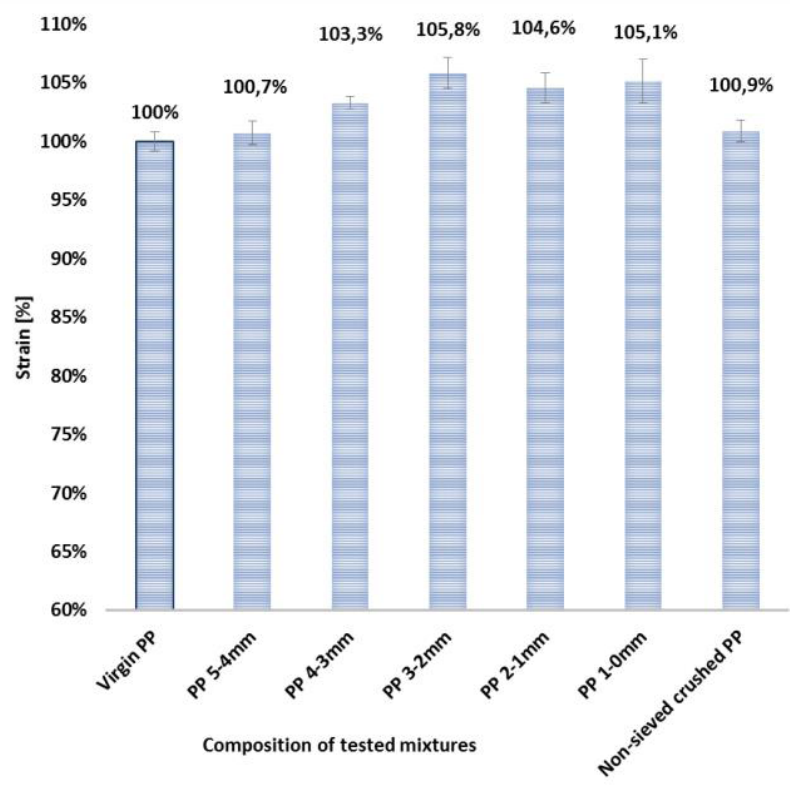

Figure 6. Strain.

\section{Summary}

The main objective of this study was to define the influence of particle size of recycled material with a filler. This filler is glass fiber. The polymeric matrix used was polypropylene PP. Polymer waste from industrial products was crushed, followed by sieving. Thus combination of mixtures were obtained, which differed from each other in particular size of the individual mixtures. These mixtures contain glass filler and for example very small particles contain very short fibers. This way prepared and processed mixtures were subjected to tensile tests.

From the viewpoint of tensile behavior for all prepared mixtures was observed decrease of stiffness and strength. For the elastic modulus there was quite a large drop in values for mixtures with small particles, this is decrease $25 \%$. The presence of small particles of recycled material had same impact to ultimate strength.

Adverse change in tensile behavior was further confirmed by a larger elongation of test specimens. The values of elongation increased gradually with decreasing particle size.

Results showed applicability recycled material with larger particles. For mixtures of dust and small particles of $2-1 \mathrm{~mm}$ is too large decrease in tensile properties. These particles contains only a very small part of the total weight of the whole non-sieved crushed mixture and causing a large drop of tensile properties.

This decrease is mainly due to the shortening of fiberglass grinding. Because of the pure polymer without glass fibers occurs after the first recycling only to reduce the tensile properties only on a smaller scale. [8, 9] Therefore, if they were removed from the crushed mixture, there would be no great reduction in tensile properties.

\section{Acknowledgment}

This paper is supported by the internal grant of TBU in Zlin No. IGA/FT/2016/010 funded from the resources of specific university research and by the Ministry of Education, Youth and Sports of the Czech Republic within the National Sustainability Programme project No. LO1303 (MSMT-7778/2014) and also by the European Regional Development Fund under the project CEBIA-Tech No. CZ.1.05/2.1.00/03.0089.

\section{References}

1. L. Scelsi, A. Hodzic, C. Soutis, S.A. Hayes, S. Rajendran, M.A. Alma'adeed, R. Kahraman. A Review on Composite Materials Based on Recycled Thermoplastics and Glass Fibres. Plastics, Rubber and Composites. (2011), vol. 40, ISSN:14658011.

2. V. Goodship, Introduction to plastics recycling. 2nd ed. Shawbury, U.K.: Smithers Rapra, (2007), 174 p. ISBN 978-1-84735-078-7.

3. J. Brandrup (ed.): Recycling and recovery of plastics, Munich, Hanser Verlag, (1996).

4. M. K. Loultcheva, M. Proietto, N. Jilov and F. P. La Mantia: Polym. Degrad. Stab., (1997).

5. F. P. La Mantia. Recycling of plastic materials. Toronto: ChemTec Pub., (1993), vi, 189 p. ISBN 18-951-9803-8.

6. A. Bernasconi, P. Davoli, D. Rossin, C. Armanni. Effect of Reprocessing on the Fatigue Strength of a Fibreglass Reinforced Polyamide. Composites Part. (2007), vol. 38, no. 3 s. 710-718. ISSN:1359-835X

7. JC Arnold. Reprocessing. In: Ballie C, editor. Green composites. Polymer composites and the environment. Cambridge: CRC Press, Woodhead Publishing Ltd; (2004).

8. V. Senkerik, M. Stanek, D. Manas, M. Manas, A. Skrobak, J. Navratil. Size effect of recycled material to tensile properties of PC (2014) Advanced Materials Research, 1025-1026.

9. V. Senkerik, M. Stanek, D. Manas, M. Manas, A. Skrobak, J. Navratil. Comparison of mechanical properties of different particle sizes of recycled polycarbonate at higher temperature (2014) International Journal of Mechanics, 8 (1), pp. 268-275.

10. D. Bryce. Plastic injection molding: manufacturing process fundamentals. Dearborn, Mich.: Society of Manufacturing Engineers, (1996), xvi, ISBN 08-726-3472-8.

11. M. Ovsik, D. Manas, M. Manas, M. Stanek, K. Kyas, K., M. Bednarik, A. Mizera. Microhardness of HDPE influenced by Beta Irradiation, International Journal of Mathematics and Computers in Simulation, Volume 6, Issue 6, (2012), p. 566-574, ISSN 1998-0159. 